\title{
Study on the Difference of the Maneuvering Characteristics of a VLCC in Standstill from those of her in Running
}

\author{
Chun-Ki Lee ${ }^{\dagger}$ \\ + Research Professor, Underwater Vehicle Research Center, Korea Maritime University
}

\begin{abstract}
The objective of this paper is to make clear the difference of maneuvering characteristics of a VLCC in standstill from those of her in running. The authors made mathematic models to calculate maneuvering motions of a VLCC in standstill using various ahead engine with full rudder angle and calculated their motions in each case and compared the calculated values with those of the same vessel running in sea trial tests. The difference of motions between them is great. For example, a VLCC in standstill can achieve a great alteration of heading over 90 degrees within the distance of $0.2 \mathrm{~L}$ advance while she advances $3.0 \mathrm{~L}$ for 90 degrees turning in full running sea trial turning test. Therefore whenever a VLCC in standstill meets a vessel approaching in collision course situation in near distance, it is better and recommendable that she should use her ahead engine with full rudder to avoid collision. So "maneuvering trial tests in standstill conditions" should be added to the content of sea trial tests when a newly built VLCC commence to take sea trials, that has not been included until now.
\end{abstract}

Key words : maneuvering characteristics in standstill, maneuvering trial test in standstill, sea trial test

\section{Introduction}

At 0713 hours on 7th Dec., 2006 a floating crane barge of lifting capacity of 3000ton owned by Samsung Heavy Industry Co. Ltd collided with a fully loaded VLCC M/V Hebei Spirit(G/T 146,848ton, Oil cargo loaded 276,030ton) on the western coastal waters of South Korea. The floating crane barge(hereafter abbreviated as FCB) had been towed by three tug boats and $\mathrm{M} / \mathrm{V}$ Hebei Spirit(hereafter abbreviated as M/V H.S.) had been waiting in anchoring berth outside of Port Daesan on the west coast of Korea. The result was a great disaster of polluting all of the western coastal waters of South Korea with heavy oil spilled out from the M/V H.S. Sailing from Inchon for Geojae the towing group(FCB and three tugs) encountered with heavy weather and the towing wire of main tug boat(T-3) was suddenly parted off in the midst of collision avoiding action. About one hour before the collision occurred the master of $\mathrm{M} / \mathrm{V}$ H.S. came up on bridge and at that time the towing group was about one mile off from the bow of the anchoring vessel. Soon after he took command and conning from the watch officer and used astern engine for about 30 minutes dragging her anchor and collided with the drifting FCB in the status of $\mathrm{M} / \mathrm{V}$ H.S. following and catching up the drifting FCB which might have drifted about $160 \mathrm{~m}$ off the port side of her stern. Most of the people who professed themselves as experts of ship handling testified in the district criminal court the use of astern engine was reasonable because of advance of that class VLCC would be about $1000 \mathrm{~m}$ (about 3L) and using ahead engine to avoid collision would make dangerous collision risk. But in the view point of our actual ship handling experience, advance of a VLCC in standstill condition using her ahead engine and full rudder would be only $0.2 \mathrm{~L}$ at largest to turn her heading over 90 degrees. Therefore the authors investigated turning of a VLCC in standstill status and made math. Models for computing the advance and turning of heading angle and computed the values of motions of M/V H.S. in standstill using various ahead engine with full rudder. The authors compared the computed values with those of the same vessel M/V H.S. got at sea trial test of half and full speed and found the difference between them are so great that the authors were surprised at the great difference and suggest to add a additional test item "maneuvering characteristics of a VLCC in standstill" to the contents of sea trial tests for a newly built vessel in shipyard, which has not been included until today. Then the tested result could be greatly helpful in taking collision avoiding maneuvering actions of a standing vessel in standstill or in anchoring(Yoon, 2002).

\footnotetext{
† Corresponding author : Chun-ki Lee, leeck@hhu.ac.kr 051) 410-4709
} 


\section{Mathematic models for computing maneuvering motions of a vessel in standstill(Yoon, 2008; Yoon, 2002)}

\subsection{Propulsive inertia}

Propulsive inertia is that a vessel in standstill commences to move ahead using her engine and gets a constant speed after running some distance in a time. Increasing speed makes increasing resistance and when the engine thrust equals to the resistance of hull a constant speed will be attained. This inertia can be manifested with distance advanced and time elapsed after engine started ahead operation. In this case the speed curve can be demonstrated as shown in fig. 1(a) and (b) and the distance run can be computed by integrating the speed curve.

\subsection{Mathematic models for computing propulsive inertia}

When a vessel in standstill start to move ahead using her engine, the engine thrust gets constant thrust $\mathrm{T}_{0}$ in a comparative short time interval, but considerable time length $\left(\Delta t_{2}\right)$ is needed for getting constant speed $u_{0}$ because ahead acceleration must be accumulated in considerable time for constant speed $\mathrm{u}_{0}$ (see fig. 1 ).

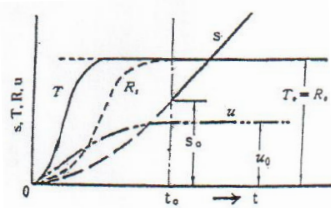

(a) various propulsive inertia curve

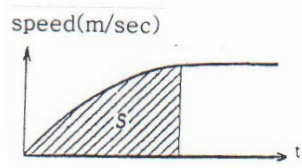

(b) $\mathrm{S}=$ advanced distance
Fig. 1 Propulsive inertia curve

2.2.1 Math. Model for computing elapsed time(Yoon, 2008; Yoon, 2002)

$\frac{\left(m+m_{x}\right)}{9.8} \frac{d u}{d t}=T_{o}-R_{o}\left(\frac{u}{u_{o}}\right)^{2}$

where, $m$ : mass of the vessel

$m_{x}$ : added mass along $\mathrm{x}$ axis

$R_{o}$ : final resistance

$T_{o}$ : final thrust

$u_{o}$ : final speed

$t=\frac{T_{s}}{2 u_{o}} L_{n} \frac{u_{o}+u}{u_{o}-u}$ where. $\quad T_{s}=\frac{u_{o}^{2}\left(m+m_{x}\right)}{9.8 R_{o}}$

2.2.2 Math. Model for computing advanced dist.(S)

$S=\frac{T_{s}}{2} L_{n} \frac{u_{o}^{2}}{u_{o}^{2}-u^{2}}$

2.2.3 Math. Model for computing turning inertia

Turning inertia means angular acceleration, velocity and quantity of alteration of heading at a time elapsed after ordered a full rudder.

(1) Equation of turning motion

$\left(I_{z}+i_{z}\right) d \dot{\phi}=$ Rudder moment-Resisting moment

where, $\mathrm{I}_{z}:$ moment of inertia around $z$ axis

$i_{z}$ : added moment of inertia around $z$ axis

Rudder moment $\left(\mathrm{M}_{\mathrm{t} 1}\right)$ is as follows:

$M_{t 1}=2.2 \times \frac{1}{2} \rho_{w} A_{R} \nu_{w}^{2} \sin \theta \cos \theta \times \frac{L_{p p}}{2}$

Resisting moment $\left(M_{t 2}\right)$ is as follows:

There are two kinds of resisting moment.

(a) Turning resisting moment $\left(M_{t 21}\right)$ due to angular velocity.

$M_{t 21}=0.0156 \rho_{w} d_{m} \rho^{\prime 2} L_{p p}^{4}$

Where, $\rho_{w}$ : water density

$d_{m}:$ mean draft

$\dot{\phi} \quad$ : angular velocity

$L_{p p}:$ length between perpendicular

(b) Resisting moment $\left(M_{t 22}\right)$ due to air resistance.

Here we disregard this resisting moment.

(2) Math. Model for computing angular velocity

$\dot{\phi}(t)=\dot{\phi}_{0} \times \frac{e^{\alpha_{o} t}-1}{e^{\alpha_{o} t}+1}$

Where, $\dot{\phi}_{o}$ : final angular velocity under a constant speed using full rudder angle $\left(35^{\circ}\right)$

$\alpha_{0}: \frac{I_{z}+i_{z}}{2 \sqrt{m_{o} C}}$ 
Where, $m_{0}$ : rudder making moment under a constant speed with $35^{\circ}$ rudder angle

$\mathrm{C}$ : resisting moment coefficient to square of angular velocity $\left(\dot{\phi}^{2}\right)$

(3) Math. Model for computing quantity of heading alteration

$$
\phi(t)=\frac{\dot{\phi}_{0}}{d_{0}} L_{n} \frac{\dot{\phi^{2}}}{\dot{\phi}_{0}^{2}-\dot{\phi}^{2}}
$$

can be computed by integrating formula(7).

\section{Computation of numerical values of maneuvering motions of $M / V$ H.S. in standstill using ahead engine with full rudder angle $\left(35^{\circ}\right)$}

\subsection{Ship's particulars}

Name : Hebei Spirit (VLCC)

Flag : Hong Kong, Port of Registry : Hong Kong G/T : 146,848 ton, $\quad L \times B \times d: 322 \times 58 \times 27.9(m)$

Draft : 19.23m, Disp. : 292,858ton

3.2 Main engine power, various data and etc.

3.2.1 Main engine

MCR $: 28,000 B H P \times 68 R P M$

NOR $: 25,200 B H P \times 65 R P M$

Table 1 Various data for main engine operation(Yoon et al., 2008)

\begin{tabular}{|c|c|c|c|c|c|}
\hline $\begin{array}{c}\text { Engine } \\
\text { order }\end{array}$ & $\begin{array}{c}\text { Power } \\
(\mathrm{BHP})\end{array}$ & RPM & $\begin{array}{c}\text { Speed } \\
(\mathrm{kt})\end{array}$ & $\begin{array}{c}\text { Thrust } \\
(\text { ton })\end{array}$ & $\begin{array}{c}\text { Remark } \\
(\%)\end{array}$ \\
\hline Full ahead & 25,200 & 65 & 16 & 172 & 100 \\
\hline Half ahead & 17,640 & 49 & 14 & 98 & 70 \\
\hline Slow ahead & 12,600 & 40 & 12.7 & 65 & 50 \\
\hline $\begin{array}{c}\text { Dead slow } \\
\text { ahead }\end{array}$ & 7,560 & 32 & 7.9 & 42 & 30 \\
\hline
\end{tabular}

The various horse powers of main engine in table 1 were taken from sea trial test and the full ahead engine thrust $\left(T_{0}\right)$ was computed with following formula.

$$
T_{0}=\frac{B H P}{0.514 V_{0}} \times 75 \times 0.75 \div 1000
$$

Where, $V_{0}$ : full ahead speed (kt) and other class engine thrust was computed by the rate of the square of R.P.M.
3.3 Result of computations of numerical motion values of $\mathrm{M} / \mathrm{V}$ H.S. in standstill

The details of numerical computations are in attached sheet I. Using various class of ahead engine with full rudder angle $\left(35^{\circ}\right)$, we got the motion values as manifested in table 2. The values of maneuvered motion are numerical values at the time of $180 \mathrm{sec}$. elapsed after the engine started to operate with full rudder angle.

Table 2 Computed values of motion in $180 \mathrm{sec}$.

\begin{tabular}{|c|c|c|c|c|c|}
\hline $\begin{array}{c}\text { Engine } \\
\text { class }\end{array}$ & $\begin{array}{c}\text { Speed } \\
\text { (kt) }\end{array}$ & $\begin{array}{c}\text { Advance } \\
\text { (m) }\end{array}$ & $\begin{array}{c}\text { Angular } \\
\text { velocity } \\
\text { (deg./sec) }\end{array}$ & $\begin{array}{c}\text { Angular } \\
\text { alteration } \\
\text { (deg.) }\end{array}$ & Remark \\
\hline $\begin{array}{c}\text { Slow } \\
\text { ahead } \\
\text { engine }\end{array}$ & 0.7 & 32 & $0.79^{\circ}$ & $100^{\circ}$ & $\begin{array}{c}\text { Anchored vessel } \\
\text { can use engine } \\
\text { and rudder as in } \\
\text { anchoring }\end{array}$ \\
\hline $\begin{array}{c}\text { Half } \\
\text { ahead } \\
\text { engine }\end{array}$ & 0.87 & 40 & $0.89^{\circ}$ & $111^{\circ}$ & $" \prime$ \\
\hline $\begin{array}{c}\text { Full } \\
\text { ahead } \\
\text { engine }\end{array}$ & 1.2 & 55 & $1^{\circ}$ & $139^{\circ}$ & $"$ \\
\hline
\end{tabular}

4. Comparison of motion values of a VLCC in standstill with those of the same vessel taken in half and full speed sea trial test of turning(Yoon et al,. 2008)
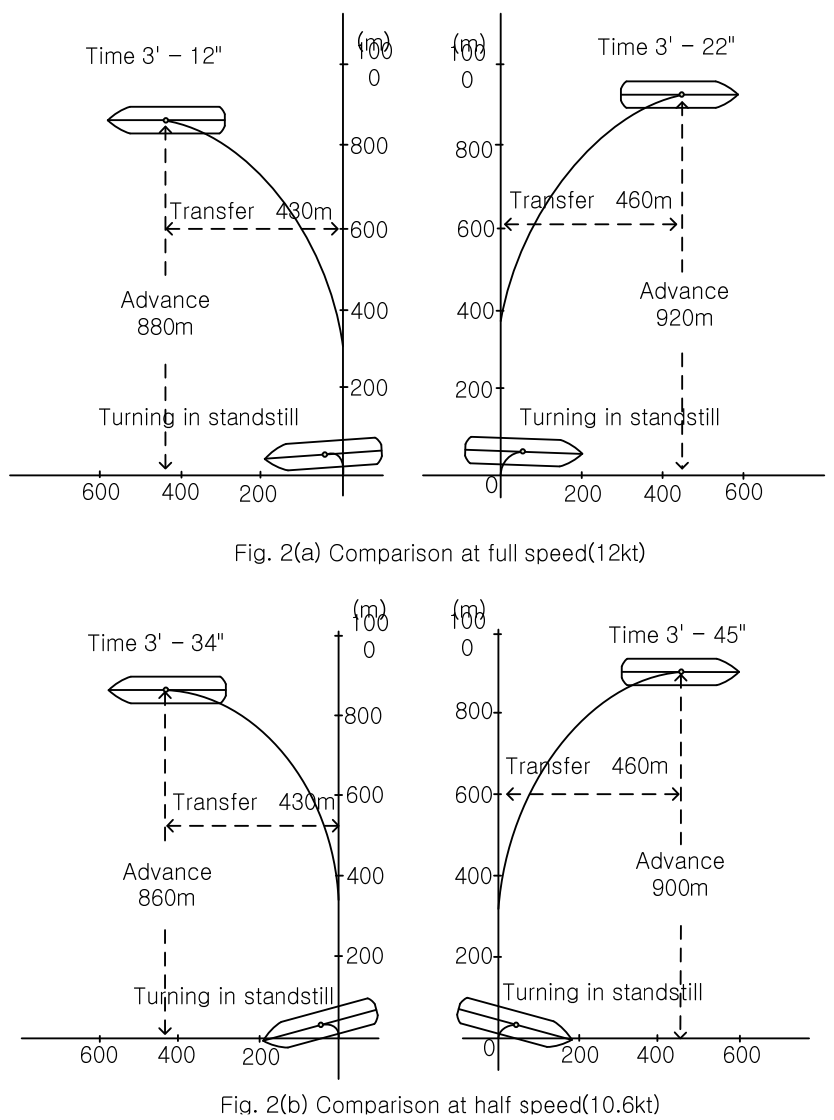

Fig. 2 Comparison of motion values of a VLCC 
Fig. 2 shows clearly so great quantitative difference between maneuvering motion of the same vessel in standstill status and half or full speed running status that we are also surprised at seeing the comparison.

In fig.2 full and half speed turning characteristics are taken from the results of sea trial tests of M/V H.S. and turning characteristics in standstill status are taken from our calculations which have been cirtified by simulations.

\section{The causes of making maneuvering characteristic difference}

1) The position of ship's pivoting point location

Static pivoting point of a vessel, which we might call as such, turning in standstill status is near the center of gravity(at the point of about 12\% forward of ship's length from $G$ point), while dynamic pivoting point of the same vessel is near the bow(at the point of about 15\% afterward from the bow).

2) The virtual radius of gyration of a vessel turning in half or full speed running status is greater than that of the same vessel turning in standstill status.

3) Therefore the resisting moment of a turning vessel in half or full speed running status is far greater than that of the same vessel turning in standstill(rate : about 100 to 40).

From above mentioned reason the great maneuvering characteristic difference comes. A long experienced excellent master or pilot often uses the characteristic difference in actual ship handling practice in harbor water area. We call it "turning at the original spot" that is, we turn a vessel using half or more ahead engine with full rudder in a short time making no advance and transfer.

\section{Conclusions}

1) Master's misunderstanding that the maneuvering characteristics of a VLCC in standstill would be same as those of her in running might invite a great disastrous sea accident which he could have avoided using ahead engine with full rudder angle.

2) Therefore we had better include a additional sea trial test item which we may call "maneuvering test in standstill status" to the contents of sea trial tests when we commence to take various sea trial tests after a VLCC is completely built in a shipyard, that has not been included until today.

\section{Acknowledgements}

This research was supported by Basic Science Research Program through the National Research Foundation of Korea(NRF) funded by the Ministry of Education, Science and Technology (2009-0071467) and supported by UVRC (Underwater Vehicle Research Center).

\section{References}

[1] Clack, I. C. (2005), Ship dynamics for mariners, The nautical institute of UK. pp 117 118.

[2] Hisaichi, K. H. (1966), Ship handling in harbor water area. pp $13 \sim 15$.

[3] Yoon, J. D. (1977), A study on the quantitative analysis of a ship's collision avoiding action by using the maneuvering indices, Journal of Korea Institute Navigation, pp 42 43.

[4] Yoon, J. D. (2008), Theory and practice of ship handling, pp 116.

[5] Yoon, J. D. (2002), Theory and practice of VLCC handling, pp 201 205.

[6] Yoon, J. D. (2008), Study on the cause of collision between M/V Hebei Spirit and Floating crane barge of Samsung Heavy Industries Co., Ltd, KINPR.

\section{ATTACHED SHEET I Propulsive and turning inertia calculation(Yoon et $\mathrm{al},$. 2008)}

Numerical calculations on the propulsive and turning inertia have been carried out on slow, half and full ahead engine with rudder angle in $180 \mathrm{sec}$, and the details of numerical calculation are as follows(Yoon et al,. 2008) :

(1) The velocity on slow ahead engine in 180 sec.

$$
\begin{aligned}
& T_{S}=\frac{u_{0}^{2}\left(m+m_{x}\right)}{9.8 R_{0}} \\
& 180=\frac{14,475}{2 \times 5.35} L_{n} \frac{5.35+u}{5.35-u} \\
& u=0.355 \mathrm{~m} / \mathrm{s}=0.70 \mathrm{kt}
\end{aligned}
$$

(2) The advance on slow ahead engine in $180 \mathrm{sec}$.

$S=\frac{T_{s}}{2} L_{n} \frac{u_{o}^{2}}{u_{o}^{2}-u^{2}}$

$S=\frac{14475}{2} L_{n} \frac{(5.35)^{2}}{(5.35)^{2}-(0.355)^{2}}=32 \mathrm{~m}$ 
(3) The velocity on half ahead engine in $180 \mathrm{sec}$

$$
\begin{aligned}
& 180=\frac{14475}{2 \times 6.0} L_{n} \frac{6.0+u}{6.0-u} \\
& u=0.447 \mathrm{~m} / \mathrm{s}=0.87 \mathrm{kt}
\end{aligned}
$$

(4) The advance on half ahead engine in $180 \mathrm{sec}$.

$$
S=\frac{14475}{2} L_{n} \frac{6^{2}}{6^{2}-0.447^{2}}=40 \mathrm{~m}
$$

(5) The velocity on full ahead engine in $180 \mathrm{sec}$.

$$
\begin{aligned}
& 180=\frac{14,475}{2 \times 7} L_{n} \frac{7.0+u}{7.0-u} \\
& u=0.607 \mathrm{~m} / \mathrm{s}=1.2 \mathrm{kt}
\end{aligned}
$$

(6) The advance on full ahead engine in $180 \mathrm{sec}$.

$$
S=\frac{14475}{2} L_{n} \frac{7^{2}}{7^{2}-0.607^{2}}=55 \mathrm{~m}
$$

(7) The angular velocity on slow ahead engine in 180 sec. with full rudder angle $\left(35^{\circ}\right)$

$$
\begin{aligned}
\dot{\phi}(t) & =\dot{\phi}_{0} \times \frac{e^{\alpha_{o} t}-1}{e^{\alpha_{o} t}+1} \\
e^{\frac{180}{37.6}} & =\frac{0.01406+\dot{\phi}}{0.01406-\dot{\phi}} \\
\dot{\phi}(180) & =0.0138 \mathrm{rad} / \mathrm{sec}=0.79^{\circ} / \mathrm{sec}
\end{aligned}
$$

$$
\begin{aligned}
& \phi(t)=\frac{\dot{\phi}_{0}}{\alpha_{0}} L_{n} \frac{\dot{\phi}^{2}}{\dot{\phi}_{0}^{2}-\dot{\phi}^{2}} \\
& \phi(180)=\frac{0.01406}{\frac{1}{37.6}} L_{n} \frac{1.01406^{2}}{1.01406^{2}-0.0138^{2}} \\
& \phi(180)=1.7480 \mathrm{rad}=100^{\circ}
\end{aligned}
$$

(9) The angular velocity on half ahead engine in 180 sec. with full rudder angle $\left(35^{\circ}\right)$

$$
\begin{aligned}
& \frac{t}{e^{34.132}}=\frac{0.0155+\dot{\phi}}{0.0155-\dot{\phi}} \\
& \dot{\phi}(t)=\frac{0.0155\left(e^{\frac{t}{34.132}}-1\right)}{\left(e^{\frac{t}{34.132}}+1\right)} \\
& \dot{\phi}(180)=0.0155 \mathrm{rad} / \mathrm{sec}=0.89^{\circ} / \mathrm{sec}
\end{aligned}
$$

(10) The angular alteration on half ahead engine in $180 \mathrm{sec}$. with full rudder angle $\left(35^{\circ}\right)$

$$
\phi(180)=\frac{0.0155}{\frac{1}{34.132}} L_{n} \frac{0.0155^{2}}{0.0155^{2}-0.0153^{2}}
$$

$$
\phi(180)=1.936 \mathrm{rad}=111^{\circ}
$$

(11) The angular velocity on full ahead engine in $180 \mathrm{sec}$ with full rudder angle $\left(35^{\circ}\right)$

$$
\dot{\phi}(t)=0.01769 \frac{\left(e^{\frac{t}{29.907}}-1\right)}{\left(e^{\frac{t}{29.907}}+1\right)}
$$

$\dot{\phi}(180)=0.01769 \mathrm{rad} / \mathrm{sec}=1.0^{\circ} / \mathrm{sec}$

(12) The angular alteration on full ahead engine in 180 sec. with full rudder angle $\left(35^{\circ}\right)$

$$
\begin{aligned}
& \phi(180)=\frac{0.01769}{\frac{1}{29.907}} L_{n} \frac{0.01769^{2}}{0.01769^{2}-0.01768977^{2}} \\
& \phi(180)=2.428 \mathrm{rad}=139^{\circ}
\end{aligned}
$$

\section{ATTACHED SHEET II}

Math. models for computation of angular velocity and angular change(alteration of course) of ship's heading

We can make math. models for computation of angular velocity $\dot{\phi}(t)$ and alteration of ship's heading $\phi(t)$ from moment equation(1)

$\left(I_{z}+i_{z}\right) \frac{d \phi}{d t}=$ Rudder moment-Resisting moment (1) Solving equation(1) we get equation(2).

$$
\dot{\phi}(t)=\dot{\phi}_{0} \times \frac{e^{\alpha_{o} t}-1}{e^{\alpha_{o} t}+1}
$$

From equation(2),

$$
\begin{aligned}
& d \phi=\dot{\phi}_{0} \frac{f-1}{f+1} d t \\
& \text { where, } f=e^{\alpha_{o} t}, \quad \frac{d f}{d t}=\alpha_{0} e^{\alpha_{0} t}, d t=\frac{d f}{\alpha_{0} f} \\
& d \phi=\dot{\phi}_{0} \frac{f-1}{f+1} \frac{d f}{\alpha_{0} f}=\frac{\phi_{0}}{\alpha_{0}} \frac{f-1}{(f+1) f} d f=\frac{\phi_{0}}{\alpha_{0}}\left(\frac{2}{f+1}-\frac{1}{f}\right) d f
\end{aligned}
$$


$\phi(t)=\frac{\phi_{0}}{\alpha_{0}}\left[L_{n}(f+1)^{2}-L_{n} f\right]+C$

when $t=0, \phi(0)=0, f=e^{\alpha_{0} t}=1$

$\therefore C=-\frac{\dot{\phi}_{0}}{\alpha_{0}} L_{n} 4$

$\phi(t)=\frac{\dot{\phi}_{0}}{\alpha}\left[L_{n}(f+1)^{2}-L_{n} f-L_{n} 4\right]$

$\phi(t)=\frac{\dot{\phi}_{0}}{\alpha_{0}} L_{n} \frac{(f+1)^{2}}{4 f}$

$L_{n} f=L_{n} \frac{\dot{\phi}_{0}+\phi}{\dot{\phi}_{0}-\phi}, f=\frac{\dot{\phi}_{0}+\dot{\phi}}{\dot{\phi}_{0}-\dot{\phi}}$.

Inserting above $\mathrm{f}$ relation into formula(3) we get formula(4).

$$
\begin{aligned}
& \phi(t)=\frac{\dot{\phi}_{0}}{\alpha_{0}} L_{n} \frac{\left(\frac{2 \dot{\phi}_{0}}{\dot{\phi}_{0}-\dot{\phi}}\right)^{2}}{4 \frac{\left(\dot{\phi}_{0}+\dot{\phi}\right)}{\left(\dot{\phi}_{0}-\dot{\phi}\right)}} \\
& \phi(t)=\frac{\dot{\phi}_{0}}{\alpha_{0}} L_{n} \frac{\dot{\phi}^{2}}{\dot{\phi}_{0}^{2}-\dot{\phi}^{2}}
\end{aligned}
$$

Received 17 September 2009

Revised 27 November 2009

Accepted 8 December 2009 